\title{
Creep-Induced Phase Instability and Microstructure Evolution of a Nearly Lamellar Ti-45Al-8.5Nb-(W, B, Y) Alloy
}

\author{
Xuyang Wang ${ }^{1} \cdot$ Jieren Yang ${ }^{1,2} \cdot \mathrm{Rui} \mathrm{Hu}^{1,2} \cdot \mathrm{Zitong} \mathrm{Gao}^{1} \cdot$ Jinguang $\mathrm{Li}^{1} \cdot \mathrm{Hengzhi} \mathrm{Fu}^{1}$
}

Received: 16 March 2020 / Revised: 24 April 2020 / Accepted: 15 May 2020 / Published online: 24 July 2020

(C) The Chinese Society for Metals (CSM) and Springer-Verlag GmbH Germany, part of Springer Nature 2020

\begin{abstract}
Microstructure degradation and stress-induced transformation of a high $\mathrm{Nb}$-containing TiAl alloy with nearly lamellar microstructure during creep were investigated. Tensile creep experiments were performed at 800,850 and $900{ }^{\circ} \mathrm{C}$ under $150 \mathrm{MPa}$ in air. Microstructures before and after creep tests were examined using scanning and transmission electron microscopy (SEM and TEM). Dislocations within the lamellar structure and $\beta_{0}(\omega)$ region and twin intersection in massive $\gamma$ grains were investigated. Dislocation sliding played a critical role in the deformation of $\omega_{\mathrm{o}}$ phase, which preferentially occurred on the $(0002) \omega_{\mathrm{o}}$ plane. Possible deformation mechanisms were revealed. A stress-induced $\gamma \rightarrow \alpha_{2}$ phase transformation took place during the creep test at 850 and $900{ }^{\circ} \mathrm{C} . \alpha_{2}$ lamella could directly decompose into the $\omega_{\mathrm{o}}$ phase at $850{ }^{\circ} \mathrm{C}$. The instability of high-temperature microstructure can weaken the creep resistance and promote the plastic deformation of the lamellar matrix, thus could be detrimental to the creep properties. The correlations between creep properties and microstructure instability were discussed.
\end{abstract}

Keywords TiAl based alloy $\cdot$ Creep $\cdot$ Microstructural stability $\cdot$ Transmission electron microscopy (TEM)

\section{Introduction}

TiAl alloys have been considered as lightweight materials, which have been applied in low-pressure gas-turbine blades and automotive industries $[1,2]$. To achieve a balance of strength and ductility, some refractory elements $(\mathrm{Cr}, \mathrm{Nb}, \mathrm{V}$, Mo, etc.) have been added to the two-phase $\left(\alpha_{2}+\gamma\right)$ alloys. $\mathrm{Nb}$ is a commonly alloying element because of its ability to improve oxidation resistance and mechanical properties at evaluated temperatures. The high $\mathrm{Nb}$-containing TiAl alloys with a baseline composition of Ti-(42-45)Al-(5-10) Nb have been thought to have the potential to remarkably heighten the service temperature [3].

Available online at http://link.springer.com/journal/40195.

Jieren Yang

yangjieren@nwpu.edu.cn

1 State Key Laboratory of Solidification Processing, Northwestern Polytechnical University, Xi'an 710072, China

2 Shaanxi Key Laboratory of High-Performance Precision Forming Technology and Equipment, Northwestern Polytechnical University, Xi'an 710072, China
All of the envisaged applications for TiAl alloys are within the temperature-stress regime, such as low-pressure turbine in aeroengines. Therefore, the creep resistance and structural stability are two important prerequisites in applications. According to previous studies, a significant amount of $\beta_{\mathrm{o}}$ phase is contained in such alloys. Non-closepacked hexagonal $\omega$-related phases, such as equilibrium $\omega_{\mathrm{o}}$ and its precursor variants $\omega^{\prime}$ or $\omega^{\prime \prime}$, are coexisted with $\beta_{\mathrm{o}}$ phase. Schloffer et al. [4] found that the $\omega_{\mathrm{o}}$ phase is the hardest phase in TNM alloy. Generally, the $\omega_{\mathrm{o}}$ phase was thought to be extremely brittle and thus a harmful constituent in the microstructure. The $\beta_{\mathrm{o}}$ phase is softer than the $\alpha_{2}$ and $\gamma$ phases at elevated temperatures due to its more open bcc structure and could reduce the creep resistance [5]. The $\beta_{\mathrm{o}}$ and the $\omega$-related phases are not stable, and they can transform to each other in the temperature range within 700-900 ${ }^{\circ} \mathrm{C}$ (i.e. intermediate temperature) [6]. Moreover, Ye et al. [7] found that the only one $\omega_{\mathrm{o}}$ variant exists after creep at 750 and $800{ }^{\circ} \mathrm{C}$ in a forged $\mathrm{Ti}-45 \mathrm{Al} 8.5 \mathrm{Nb}-(\mathrm{W}, \mathrm{B}$, Y) alloy.

The instability of the $\beta_{0}(\omega)$ phase has a negative influence on creep properties. Moreover, the lamellar microstructure is also unstable and would decompose significantly at intermediate temperatures. In a high $\mathrm{Nb}-\mathrm{TiAl}$ alloy, a transformation 
of $\alpha_{2} \rightarrow \omega_{\mathrm{o}}$ was observed after annealing at $850{ }^{\circ} \mathrm{C}$ for $500 \mathrm{~h}$, and the orientation relationships were confirmed [8]. The $\alpha_{2} \rightarrow \beta_{\mathrm{o}}$ transformation induced by stress was found by Wang et al. [5], which could lead to the softening of the microstructure and deteriorate the creep properties. Block $\beta_{0}(\omega)$ grains were found to be transformed by consuming both $\alpha_{2}$ and $\gamma$ lamella in a Ti-44Al-4Nb-4Hf-0.2Si-1B alloy after 1000-h exposure at $700{ }^{\circ} \mathrm{C}$ [9]. The transformation of $\alpha_{2} \rightarrow \gamma$ through perpendicular decomposition or parallel decomposition was reported in several TiAl alloys $[10,11]$. Thus, the instability of $\beta_{\mathrm{o}}(\omega)$ and the lamellar microstructure may significantly affect the creep property of TiAl alloys, especially above the brittle-ductile transition temperature (BDTT) [12]. Moreover, the creep-induced decomposition of $\alpha_{2} \rightarrow \gamma$ could contribute to the increase of the creep rate [13].

However, the effect of the microstructure degeneration under the temperature-stress condition on the creep properties is still scarce. Therefore, the detailed investigation is required for understanding the microstructural stability in high Nb-containing TiAl alloys. In the present study, an ascast $\mathrm{Ti}-45 \mathrm{Al}-8.5 \mathrm{Nb}-(\mathrm{W}, \mathrm{B}, \mathrm{Y})$ alloy with a nearly lamellar (NL) microstructure was tested at $800-900{ }^{\circ} \mathrm{C}$ under $150 \mathrm{MPa}$. The microstructure evolution and the effects on the creep properties have been investigated.

\section{Experimental}

TiAl ingot with a composition of Ti-45Al-8.5Nb-0.2W-0.2B-0.02Y (at\%) was produced by a plasma cold hearth melting furnace. Then, specimens with a gauge dimension of $10 \mathrm{~mm} \times 4.5 \mathrm{~mm} \times 2.5 \mathrm{~mm}$ were wired-cut from the as-cast ingot (as illustrated in Fig. 1), and the surfaces were mechanically ground. Tensile creep tests were carried out at 800,850 and $900{ }^{\circ} \mathrm{C}$ under a constant load of $150 \mathrm{MPa}$. All samples failed in the gauge section. The temperatures at the gauge section of the specimen were within $\pm 1{ }^{\circ} \mathrm{C}$ of the preset temperature. In order to retain the deformation microstructure, the specimens after failure

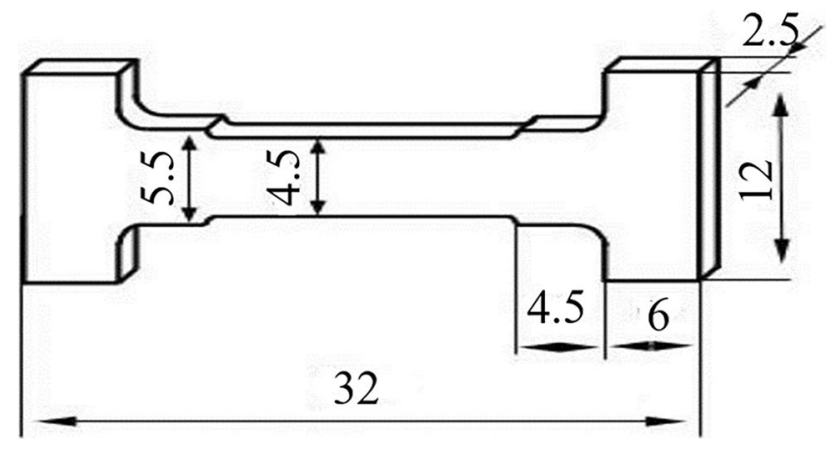

Fig. 1 Schematic of the creep samples used in this study were immediately taken out and rapidly cooled to room temperature.

The detailed microstructures were characterized on a VEGATESCAN scanning electron microscopy (SEM) in the backscattered electron (BSE) mode operating at $20 \mathrm{kV}$. To provide a full understanding of the deformation behaviors, transmission electron microscopy (TEM) analysis was carried on an FEI Talos F200X TEM operating at $200 \mathrm{kV}$. TEM thin foils were prepared by twin-jet polishing with an electrolyte of $65 \mathrm{vol} \%$ methanol, 30 vol\% butan-1-ol and 5 vol\% perchloric acid operating at $30 \mathrm{~V}$ and $-30{ }^{\circ} \mathrm{C}$.

\section{Results and Discussion}

\subsection{As-Cast Microstructure}

The microstructure before creep testing was examined by SEM and TEM. Figure 2a shows the BSE image of the ascast microstructure. The average lamellar colony size is about $120 \mu \mathrm{m}$, and some $\beta_{\mathrm{o}}(\omega)$ and $\gamma$ grains are located at the colony boundaries, exhibiting a NL microstructure. In addition, some needle-like phase and ellipse shape particles in bright contrast are randomly distributed in the lamellar matrix. From a previous study [14], the needle-like phase is borides. The composition of the ellipse shape particles was analyzed by EDS, indicating these particles contain elements yttrium and oxygen. The content of yttrium and oxygen is 38.16 at $\%$ and 61.84 at\%, respectively. The chemical formula of this phase is close to $\mathrm{Y}_{2} \mathrm{O}_{3}$, then these particles are $\mathrm{Y}_{2} \mathrm{O}_{3}$. From Fig. 2b, the average lamellar spacing in $\alpha_{2} / \gamma$ colonies is about $86 \mathrm{~nm}$. It should be noted that the interfaces between the lamellae are sharp and straight, which is caused by the $\alpha \rightarrow \gamma$ transformation that occurs upon solidification and cooling [15].

\subsection{Creep Test Results}

The creep curves (strain-time curve) of the investigated alloy, measured at 800,850 and $900{ }^{\circ} \mathrm{C}$ under an initial stress of $150 \mathrm{MPa}$, are plotted in Fig. 3. The curves exhibit the similar stages also in many other metals: the primary creep, the minimum creep rate creep, and the tertiary creep. After the period of primary creep, the samples would undergo a minimum creep rate with a constant strain rate that persists for a long period of time. Figure 3 demonstrates that both the minimum creep rate and rupture strain are noted to significantly increase with the increment of the testing temperature. The final fracture occurred in the tertiary creep stage during which the creep rate considerably increased. From 800 to $850{ }^{\circ} \mathrm{C}$, the creep life rapidly decreases and the elongation significantly increases, indicating that the BDTT of this alloy 

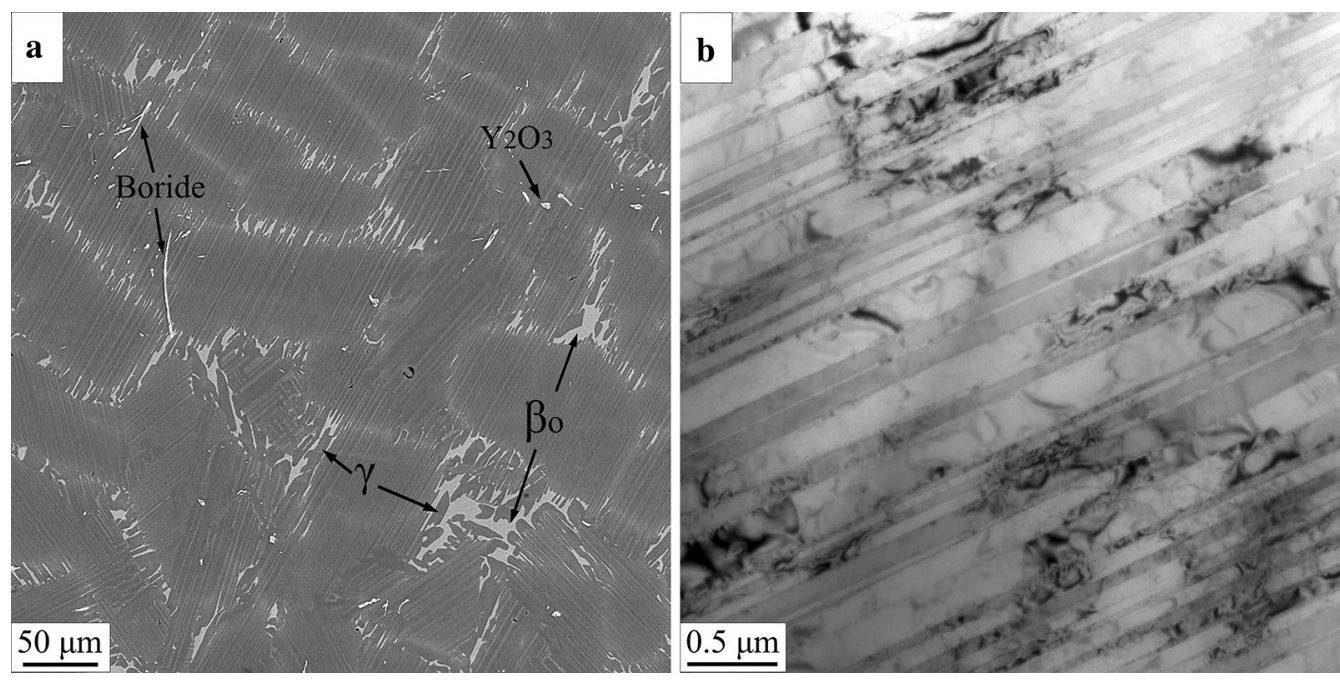

Fig. 2 a SEM-BSE image of the as-cast Ti-45Al-8.5Nb-0.2 W-0.2B-0.02Y alloy, b TEM bright-field image of the lamellar structure

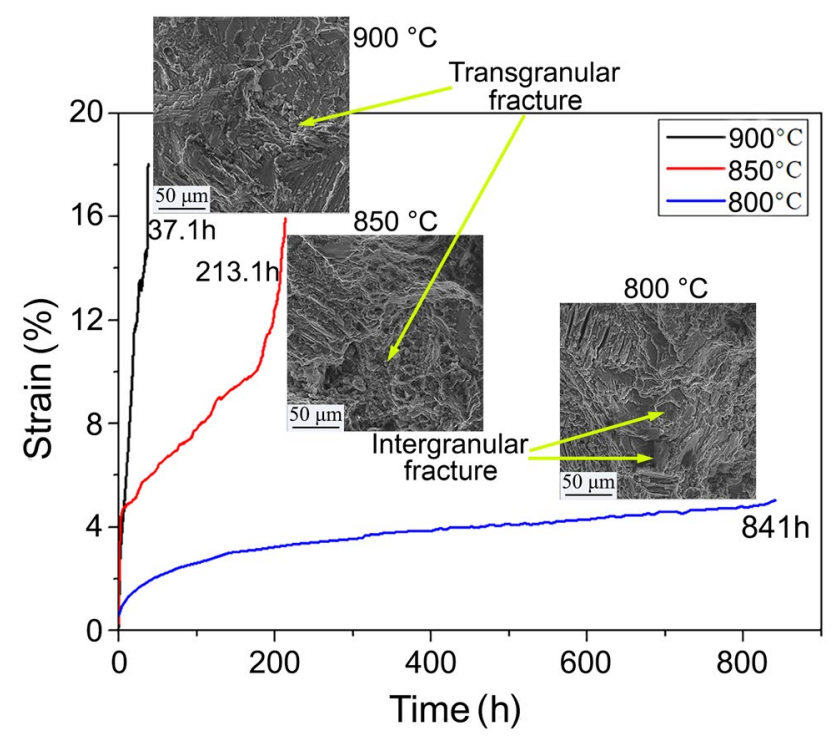

Fig. 3 Typical creep curve (strain-time) at 800,850 and $900{ }^{\circ} \mathrm{C}$ at $150 \mathrm{MPa}$

is in the temperature range of $800-850{ }^{\circ} \mathrm{C}$. At $800{ }^{\circ} \mathrm{C}$, the fracture was induced by splitting the lamellar plates through intra- and inter- lamellar colonies. The fracture morphology of the equiaxed $\gamma$ grains revealed and failed by intergranular fracture at the lamellar colony boundaries. At 850 and $900{ }^{\circ} \mathrm{C}$, the fracture surfaces became rougher as the result reported by Clemens et al. [16], and there was an absence of the interlamellar splitting between the lamellar plates. However, the equiaxed $\gamma$ grains were failed by transgranular decohesion.

\subsection{Microstructure and Phase Transformation After Creep Test at $800^{\circ} \mathrm{C}$}

After the creep test at $800^{\circ} \mathrm{C}$, the microstructure in the gauge section is shown in Fig. 4. The microstructure is stable and has a similar morphology as the as-cast state, comprising the $\alpha_{2} / \gamma$ lamellar colonies, $\beta_{\mathrm{o}}(\omega)$ and massive $\gamma$ grains located at colony boundaries, as presented in Fig. 4a. Comparing with Fig. 3a, it seems that the volume fraction of $\beta_{\mathrm{o}}(\omega)$ phase decreased after creep deformation. In addition, several voids can be found around $\mathrm{Y}_{2} \mathrm{O}_{3}$ particles, at colony boundaries and in the $\beta_{\mathrm{o}}(\omega)$ region (indicated by the arrows in Fig. 4a). The voids nucleated at colony boundaries could contribute to creep strain [13] and be responsible for the poor ductility [17]. Then, a high-resolution characterization was performed by TEM examination. As shown in Fig. 4b, the interfaces are kind of unsharp in the bright-field electron micrographs, which is due to that the dislocations were assembled at the $\alpha_{2} / \gamma$ and $\gamma / \gamma$ interfaces. During the creep test, the deformation occurred mainly in the $\gamma$ lamellae $[12,18]$ and these dislocations were generated from the lamellar interfaces [19]. This suggests that the stress concentration induced by lamellar interfaces have caused the interfaces to be both high energy sites and stress concentrators, which are consistent with the result reported by Edwards et al. [18]. When the stress concentration was enhanced, microcracks would be generated at interfaces between the lamellar plates, leading to the splitting of lamellar plates (as shown in Fig. 3). As also described in the literature [18-20], the glide of ordinary dislocations with Burgers vectors $\boldsymbol{b}=<101]$ and $\boldsymbol{b}=<11 \overline{2}$ ] is the primary deformation mode. From the selected area diffraction (SAD) pattern of the area A, the adjacent $\gamma$ lamellae are in a true-twin relationship, which is the same as in the as-cast microstructure. Figure $4 \mathrm{c}$ and $\mathrm{d}$ shows interfaces 

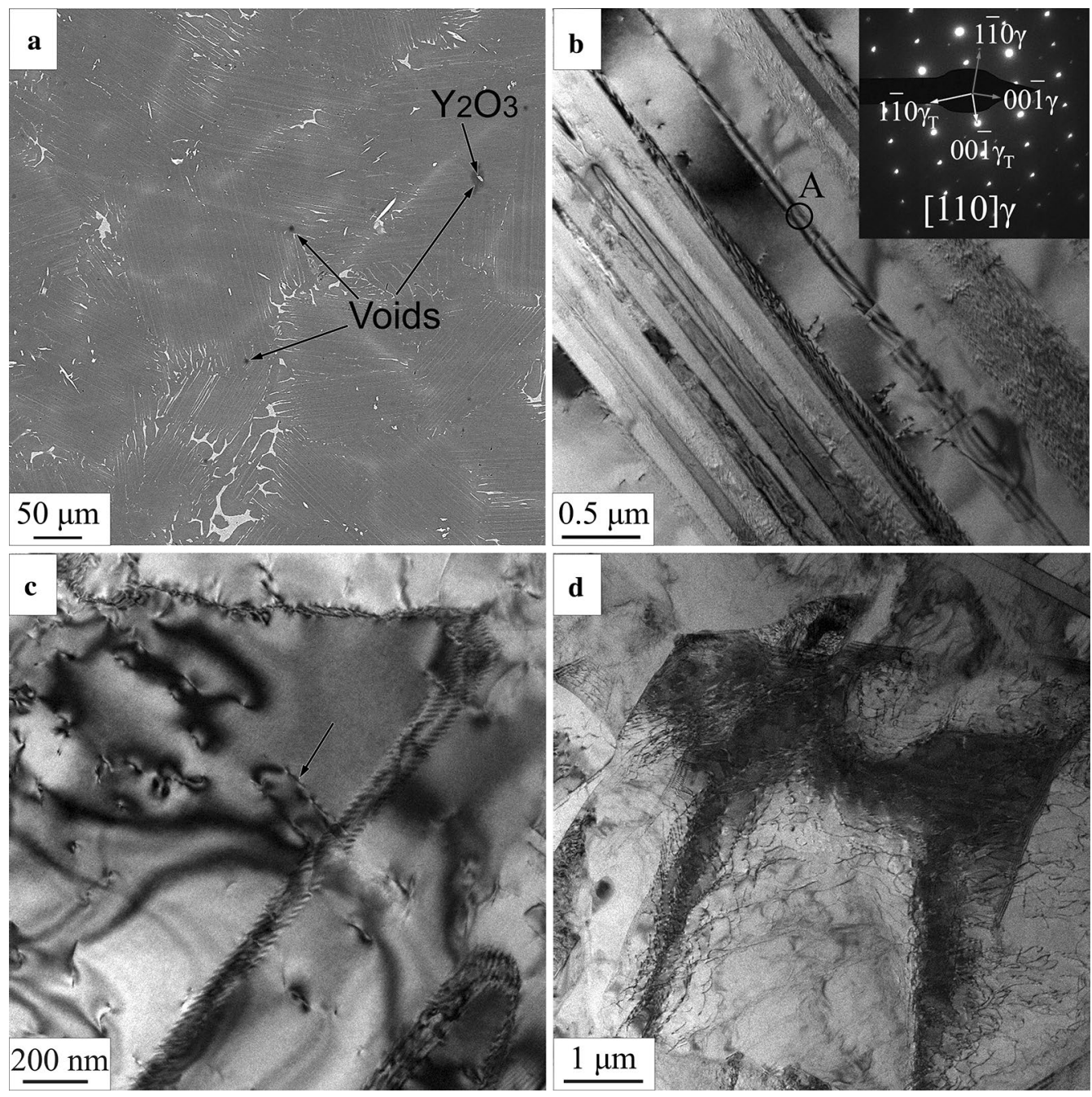

Fig. 4 Microstructure after creep test at $800^{\circ} \mathrm{C}$ : a) SEM-BSE image; $\mathbf{b}$, $\mathbf{c}$ bright-field TEM images of the lamellar structure; $\mathbf{d}$ bright-field TEM image of $\gamma$ grain located at the lamellar colony boundaries

between $\gamma$ lamellae. A loop in Fig. 4c appeared at the interface (indicated by the arrow), which should be probably generated from the interfacial dislocations and was bowed out by creep stress. A superimposed stress could release the dislocation loops from the interfaces. At elevated temperatures, the glide resistance is reduced because of thermal activation, then the emission of dislocations from lamellar interfaces is commonly enhanced. Figure $4 d$ shows that the dislocations located at the boundaries of the lamellar colonies are more intensive and more loops are emitted into the massive $\gamma$ grains. It might be speculated that the stress concentration is much more severe at the colony boundaries. Meanwhile, the emission of interfacial dislocations could relieve the stress concentration. This would enhance the creep rate and thus can be detrimental for the high-temperature performance of TiAl alloys.

The other potential deformation mode is the mechanical twinning, which plays an important role in the deformation of lamellar TiAl alloys [21]. A kind of mechanical twinning, within the massive $\gamma$ grains located at the boundaries of lamellar colonies, is revealed in Fig. 5a. The deformation is manifested by two twinning systems that intersect with each other. It is worth noting that such twin intersection strongly influences the fracture behaviors. On the one hand, crack-tip shielding caused by mechanical twinning might lead to strengthening and decelerate fast-growing cracks. On the other hand, cracks are prone to the cleavage fracture on $\{111\} \gamma$ planes [22], then microcracks may be readily generated at intersecting twin bands. At elevated temperatures, dislocation emission probably rises in the intersection process, the dislocation rearrangement surrounding the misoriented zone may occur, then the misorientation between the misoriented zone and the surrounding matrix increases. Finally, the intersection zone would transform into a new grain. Thus, it might be expected that the twin intersections could act as a precursor for recrystallization. 

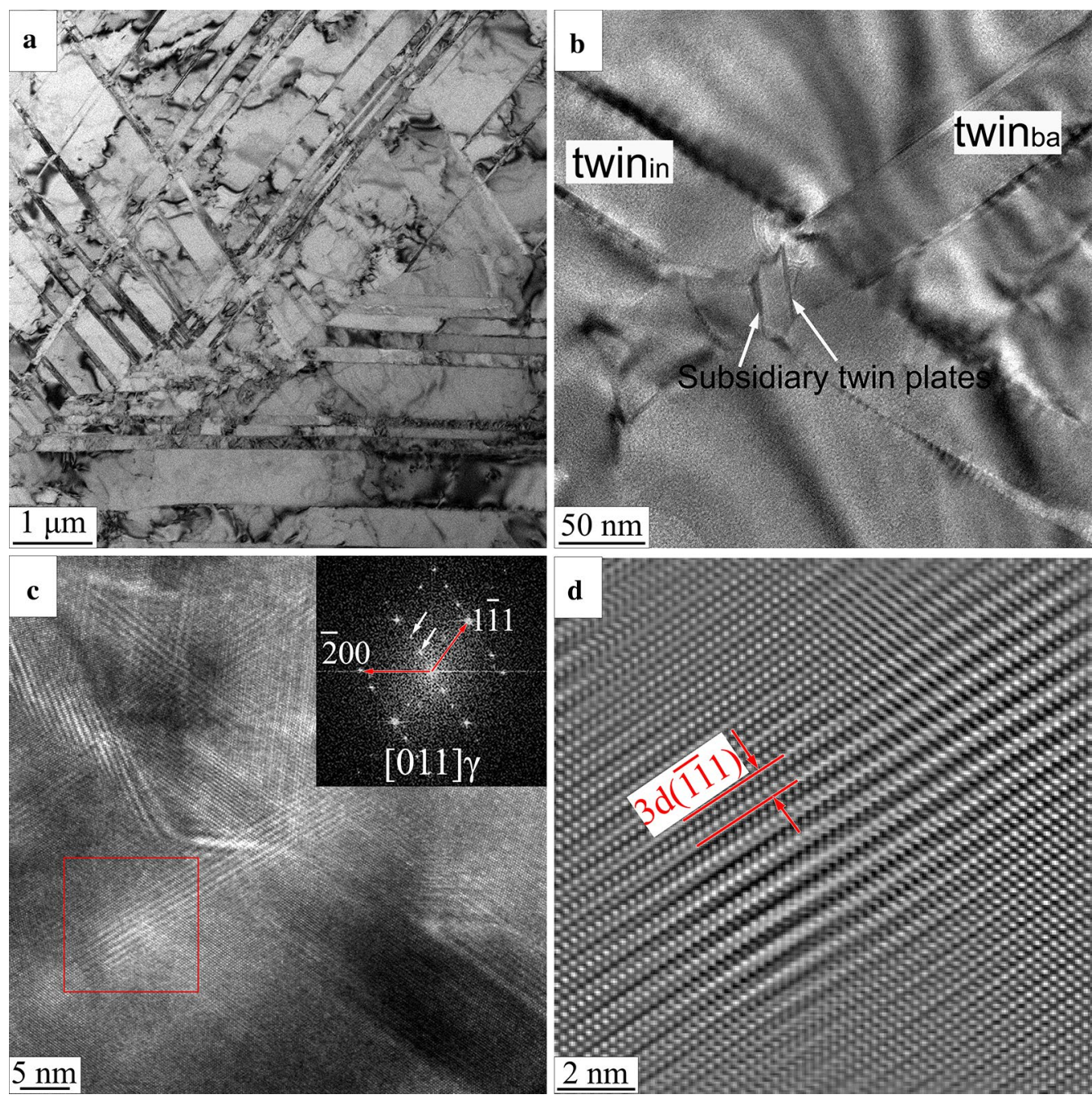

Fig. 5 a TEM image of the deformation structure after creep test at $800{ }^{\circ} \mathrm{C}$; $\mathbf{b}$ magnified image of the twin intersection; $\mathbf{c}$ high-resolution transmission electron microscope (HRTEM) of the twin intersection recorded along the common $<011] \gamma$ zone axis of twins Ti and Tb; $\mathbf{d}$ inverse transformation (IFFT) of the red box in $\mathbf{c}$

Figure $5 \mathrm{~b}$ demonstrates the detailed information of the twin intersection, showing that an incident twin $\left(\operatorname{twin}_{\mathrm{in}}\right)$ intersects a barrier twin $\left(\operatorname{twin}_{b a}\right)$. Both the twin ${ }_{i n}$ and the twin $_{\mathrm{ba}}$ were deflected after the intersection. The deflection of the twin ${ }_{\text {in }}$ follows the trace of the $\{111\}$ plane of the $\operatorname{twin}_{\mathrm{ba}}$ [23]. The shear of the $\operatorname{twin}_{\mathrm{in}}$ was accommodated by the subsidiary twin plates, which were confined within the intersection region (as indicated in Fig. 5b). Some black spots were found distributed along the interfaces between the twins and the matrix, indicating that there exists strain along the interfaces. Figure $5 \mathrm{c}$ is the HRTEM of the twin intersection recorded along the common $<011] \gamma$ zone axis. The fast Fourier transform (FFT) of the area of the red box in Fig. $5 \mathrm{c}$ is inserted at the top right corner. It was surprising that some extra spots appeared at $1 / 3(\overline{1} \overline{1} 1)$ and 2/3( $\overline{1} \overline{1} 1)$, as indicated by the white arrowhead. For clarity, the inverse transformation (IFFT) of the red box area was obtained. As can be seen in Fig. 5d, there is a variation of the contrast with a periodicity of three ( $\overline{1} \overline{1} 1)$ planes, which is similar to the 9R structure reported in Ref. [24]. Abe et al. found that such phenomena may also be caused by overlapped twins [25]. In this study, the twin intersection is overlapped by $\operatorname{twin}_{\text {in }}$ and $\operatorname{twin}_{\mathrm{ba}}$, which are in the twin relationship. As a result, the special contrast feature arises from overlapping twin-related $\gamma$ variants.

Little information was available about the deformation behavior of the $\beta_{0}(\omega)$ phases in previous studies, and the deformation of the $\beta_{0}(\omega)$ region was also investigated in this study. The deformation of the $\beta_{0}(\omega)$ region was initiated by constraint stresses [26], which was developed by the deformation of adjacent $\alpha_{2} / \gamma$ lamellar colonies and $\gamma$ grains. As shown in Fig. 6a, amounts of elliptical $\omega_{\mathrm{o}}$ particles occupy almost the whole $\beta_{\mathrm{o}}(\omega)$ region. Comparing with the as-cast microstructure [27], the $\omega_{\mathrm{o}}$ particles are not elliptical but 


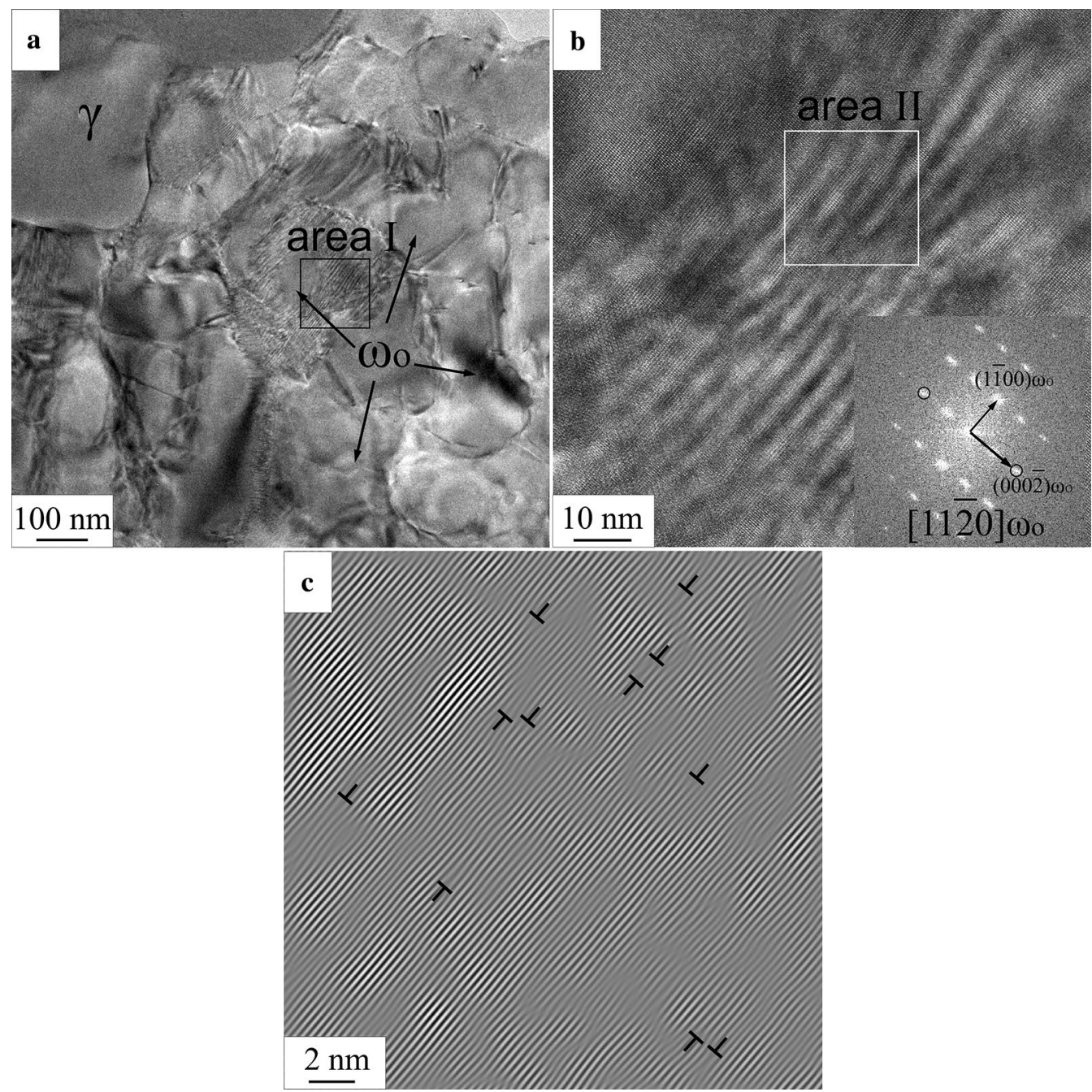

Fig. 6 a TEM image of $\beta_{\mathrm{o}}(\omega)$ region; b HRTEM recorded along the [110] $\beta_{\mathrm{o}}$ zone axis in $\beta_{\mathrm{o}}(\omega)$ region of the area I in $\mathbf{a} ; \mathbf{c}$ IFFT of area II in $\mathbf{b}$, which only shows the (0002) plane

becoming irregular and some areas with corrugated appearance appeared at the edge. Figure $6 \mathrm{~b}$ is the HRTEM of the corrugated area, showing only one $\omega_{\mathrm{o}}$ variant occupies this region (in the inset in the bottom right corner). This may be due to the strain or defects in this area. Figure $6 \mathrm{c}$ was obtained by selecting the $(000 \overline{2}) \omega_{\mathrm{o}}$ and $(0002) \omega_{\mathrm{o}}$ reflection spots, which only shows the (0002) planes of the selected region (area II) in Fig. 6b. Abundant dislocations were found in this region (in Fig. 6c), indicating that dislocation glide in the $\omega_{\mathrm{o}}$ phase preferentially occurred on (0002) planes. As a result, dislocation glide certainly significantly contributes to the deformation of the $\omega_{\mathrm{o}}$ phase at elevated temperatures.

\subsection{Microstructure and Phase Transformation at $850{ }^{\circ} \mathrm{C}$}

Figure 7 shows the microstructure after the creep test at $850^{\circ} \mathrm{C}$. Similarly, a NL microstructure was obtained, as seen in Fig. 7a. The volume fraction of the $\beta_{\mathrm{o}}(\omega)$ phase decreases after the creep test at $850{ }^{\circ} \mathrm{C}$ and is roughly the same as that at $800{ }^{\circ} \mathrm{C}$. The voids can be observed at colony boundaries and close to the $\beta_{\mathrm{o}}(\omega)$ region (indicated by arrows in Fig. 7a). Since the softest phase is the $\gamma$ phase and the $\beta_{\mathrm{o}}(\omega)$ region is the hardest [4], it is tempting to speculate that the cracks are prone to form at the boundaries between the $\gamma / \beta_{\text {o }}$ interface because of the difference of deformability. More dislocations were found within the laths (Fig. 7b) than that in Fig. 4b, and this is because larger thermal energy was provided for dislocations to emit into the laths from the interfaces. It is worth noting that the $\alpha_{2}$ lamellae in Fig. 7b are much thicker compared with that in the as-cast state and after the $800{ }^{\circ} \mathrm{C}$ testing. This phenomenon was not found in the sample annealed at $850{ }^{\circ} \mathrm{C}$ for $500 \mathrm{~h}$ in the same alloy [8], indicating that the stress plays an important role in the phase transformation of $\gamma \rightarrow \alpha_{2}$ during the creep test at $850{ }^{\circ} \mathrm{C}$. Since element oxygen is an $\alpha$ phase stabilizer in 

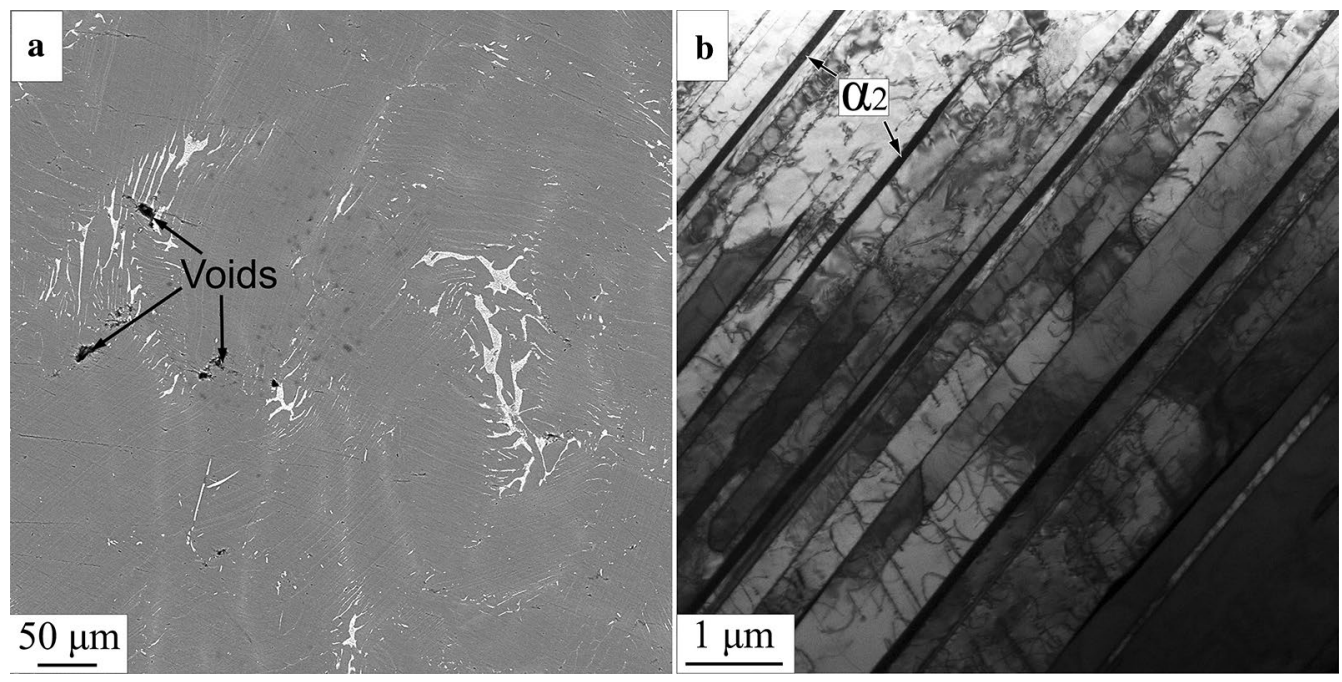

Fig. 7 Microstructures after creep test at $850^{\circ} \mathrm{C}$ : a SEM-BSE image; b bright-field TEM image of the lamellar structure

Ti/TiAl alloys, the phase transformation of $\gamma \rightarrow \alpha_{2}$ may be induced by oxygen. On the one hand, since high $\mathrm{Nb}$-containing TiAl alloys have excellent oxidation resistance, the oxide layers are extremely thin after the creep tests in this study. On the other hand, the creep time at $800{ }^{\circ} \mathrm{C}$ is much longer than that at 850 and $900{ }^{\circ} \mathrm{C}$. If this phase transformation is induced by oxygen, such phase transformation should also occur in the sample test at $800{ }^{\circ} \mathrm{C}$. So, it is more reasonable to speculate that the phase transformation of $\gamma \rightarrow \alpha_{2}$ is induced by stress.

To further investigate the lamellar structure, the lamellar structure was characterized by the high angle annular dark field (HAADF), as presented in Fig. 8a. Since $\mathrm{Al}$ enriches into $\gamma$ laths and Ti segregates in $\alpha_{2}$ laths [28], the brightness of the $\alpha_{2}$ phase is higher than that of the $\gamma$ phase. The HAADF image of $\gamma$ laths is magnified in the inset at the top right corner. The dislocations in the $\gamma$ laths show the same contrast as the $\alpha_{2}$ phase. Zhang et al. [29] found that $\mathrm{Ti}$ atoms tend to concentrate at the interface between $\gamma / \gamma$ laths. It can be concluded that $\mathrm{Ti}$ atoms are also prone to concentrate at dislocations. As mentioned in Fig. $4 \mathrm{c}$ and d, abundant interfacial dislocations were generated during the creep test at $800{ }^{\circ} \mathrm{C}$. This would lead to the increase of the Ti content at the interfaces. The $\gamma \rightarrow \alpha_{2}$ transformation can be explained from two aspects: (1) $\alpha_{2} / \gamma$ and $\gamma / \gamma$ interfaces with abundant dislocations exhibit higher free energy and can provide diffusion channels for solute atoms; (2) because Ti preferentially enriches at the interfaces of $\gamma / \gamma$ and $\alpha_{2} / \gamma$, the thermodynamic of the $\gamma \rightarrow \alpha_{2}$ phase transformation is more easily enhanced.

$\beta_{\mathrm{o}}(\omega)$ blocks have been found to form from $\alpha_{2}$ laths, as shown in Fig. 8a. Figure $8 \mathrm{~b}$ is the magnified image. This is the perpendicular decomposition of single $\alpha_{2}$ lamella into $\alpha_{2}+\beta_{\mathrm{o}}(\omega)$ sections, which is consistent with the result reported by Huang et al. [8, 9]. Dey et al. [30] claimed that the $\omega$ phase could be directly transformed from an $\alpha$ phase without an intermediate $\beta$ phase after shock deformation. Figure $8 \mathrm{c}$ is the HRTEM of the boundary between the residual $\alpha_{2}$ phase and the $\beta_{\mathrm{o}}(\omega)$ region (the yellow box in Fig. 8b). Since the $\alpha_{2}$ phase is adjacent to the $\omega_{\mathrm{o}}$ phase, the ordered $\omega_{\mathrm{o}}$ phase is also directly transformed from the $\alpha_{2}$ lath in the current alloy. The lattice parameters of the $\alpha_{2}$ and $\omega_{\mathrm{o}}$ phases are shown in Fig. 8c, the interplanar spacings of the parallel $(\overline{1} 210) \omega_{\mathrm{o}}$ and $(0002) \alpha_{\mathrm{o}}$ are $0.232 \mathrm{~nm}$ and $0.235 \mathrm{~nm}$, respectively. The corresponding FFT image is shown in Fig. 8d, and the orientation relationships between the two phases are as follows: $\langle 11 \overline{2} 0\rangle \alpha_{2} / /\langle 0001\rangle \omega_{0},\{0001\} \alpha_{2} / /\{11 \overline{2} 0\} \omega_{0}$.

As described above, the structural changes before and after creep at $850{ }^{\circ} \mathrm{C}$ are more remarkable than that at $800{ }^{\circ} \mathrm{C}$. The strain-hardens rate of a material is generally determined by the competition between the storage defects and the release of strain energy. During the creep test at $850{ }^{\circ} \mathrm{C}$, the phase transformations of $\gamma \rightarrow \alpha_{2}$ and $\alpha_{2} \rightarrow \omega_{\mathrm{o}}$ took place, which could absorb the dislocations and decrease the strain energy, leading to an additional softening of the material. The stress concentration at interfaces was relieved, and then it is unlikely to result in cracks between the lamellar plates, as mentioned in Sect. 3.2. In the steady-state creep stage, the phase transformations could result in the decrease of creep resistance of the lamellar structure. So, the fracture elongation at $850{ }^{\circ} \mathrm{C}$ is much higher than that at $800{ }^{\circ} \mathrm{C}$.

\subsection{Microstructure After Creep Test at $900{ }^{\circ} \mathrm{C}$}

The microstructure after the creep test at $900{ }^{\circ} \mathrm{C}$ is shown in Fig. 9. Figure 9a exhibits the similar microstucture as that in Figs. $4 \mathrm{a}$ and 7a. $\alpha_{2}$ lamellae in Fig. $9 \mathrm{~b}$ are also much thicker than that in the as-cast state, which demonstrates 


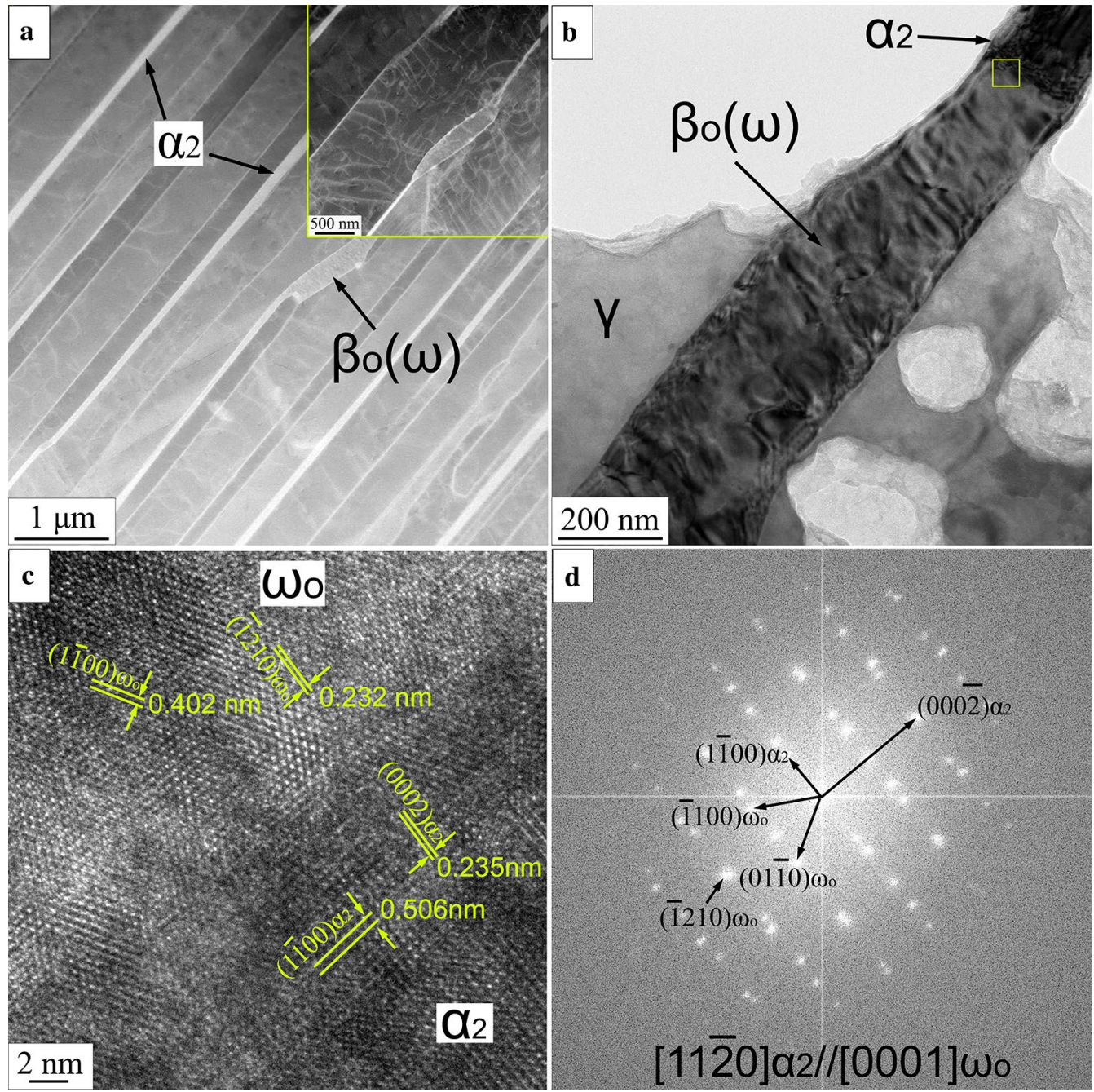

Fig. 8 a HAADF image of the lamellar structure; $\mathbf{b}$ bright-field TEM image of $\alpha_{2}$ lath, indicating that the $\beta_{0}(\omega)$ phase precipitated during the creep process; $\mathbf{c}$ HRTEM recorded along the $[11 \overline{2} 0] \alpha_{2}$ zone axis at the boundary between $\alpha_{2}$ and $\beta_{\mathrm{o}}(\omega)$ phases in b; $\mathbf{d}$ corresponding FFT of $\mathbf{c}$

that the stress-induced $\gamma \rightarrow \alpha_{2}$ transformation was proceeding during the creep test. As explained in Sect. 3.4, this would relieve the stress concentration and restrain the formation of cracks at the interfaces. No $\beta_{0}(\omega)$ region was found in $\alpha_{2}$ laths, indicating that the $\alpha_{2} \rightarrow \omega_{\mathrm{o}}$ transformation did not take place. This may be due to the insufficient creep time at $900{ }^{\circ} \mathrm{C}(37.1 \mathrm{~h})$. The black contrast area in Fig. $9 \mathrm{c}$ represents the $\beta_{\mathrm{o}}(\omega)$ phase and the elliptical particles are the $\omega_{\mathrm{o}}$ phase. The volume fraction of the $\omega_{\mathrm{o}}$ phase is much smaller than that at $800{ }^{\circ} \mathrm{C}$. The dissolution temperature of the $\omega_{\mathrm{o}}$ phase into the $\beta_{\mathrm{o}}$ phase is about $905{ }^{\circ} \mathrm{C}$ [31], the volume fraction of the $\omega_{\mathrm{o}}$ phase would decrease rapidly when approaching the dissolution temperature. Figure $9 \mathrm{~d}$ is the selected area diffraction pattern (SADP) of the $\beta_{\mathrm{o}}(\omega)$ region in (c), indicating that four $\omega_{\mathrm{o}}$ variants with different orientations exist in the $\beta_{\mathrm{o}}$ phase (two $\langle 11 \overline{2} 0\rangle \omega_{\mathrm{o}}$ and two $\langle 1 \overline{1} 02\rangle \omega_{\mathrm{o}}$ zone axis). Ye et al. [7] found that only one $\omega_{\mathrm{o}}$ variant would exist in the $\beta_{\mathrm{o}}$ region after creep, which is inconsistent with the current result. This may be also attributed to the insufficient creep time before fracture. As can be seen from Fig. 9d, the brightness of $\omega_{\mathrm{o} 1}$ is obviously lower than that of $\omega_{\mathrm{o} 2}$, manifesting that the volume fraction of $\omega_{\mathrm{o} 1}$ is much lower. It can be interpreted that $\omega_{\mathrm{o} 1}$ has been declining gradually during the creep and would disappear as the creep time increased.

\section{Conclusions}

In this work, creep behavior and microstructure stability of a Ti-45Al-8.5Nb-(W, B, Y) alloy were investigated. Microstructure degradation and stress-induced transformation were discussed. The main results are summarized as follows:

1. During the creep test at $800{ }^{\circ} \mathrm{C}$, dislocations were assembled at the colony boundaries and lamellae interfaces $\left(\alpha_{2} / \gamma\right.$ and $\left.\gamma / \gamma\right)$. The twin intersection and the mas- 


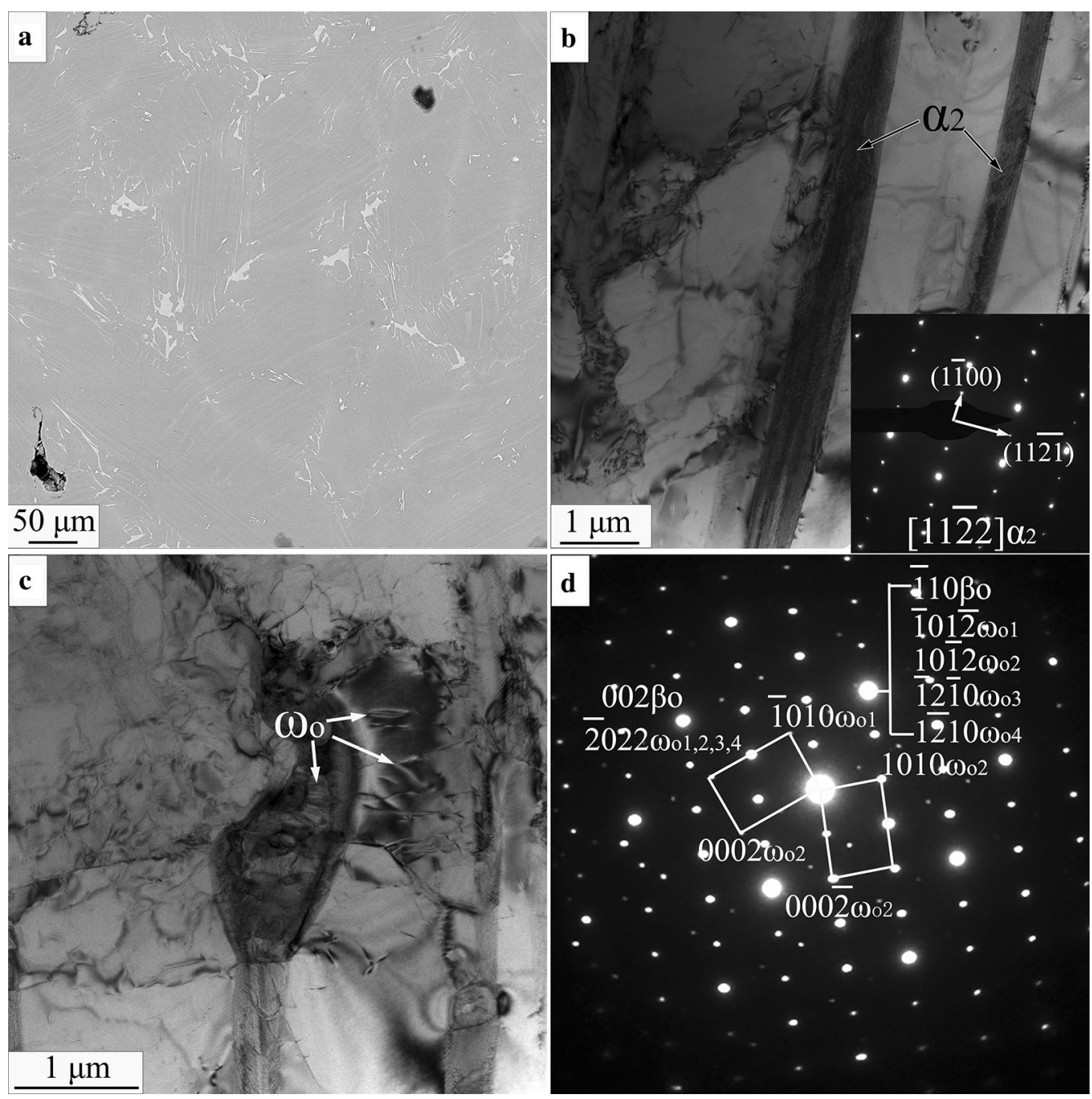

Fig. 9 Microstructures after creep test at $900{ }^{\circ} \mathrm{C}$ : a SEM-BSE image; b bright-field TEM image of the lamellar structure; $\mathbf{c}$ TEM image of the $\beta_{\mathrm{o}}(\omega)$ region; $\mathbf{d}$ SADP of the $\beta_{\mathrm{o}}(\omega)$ region in $\mathbf{c}$

sive $\gamma$ grains were also found. Dislocation glide significantly contributes to the deformation of the $\omega_{0}$ phase at elevated temperatures and the glide in the $\omega_{\mathrm{o}}$ phase preferentially occurs on the $(0002) \omega_{\mathrm{o}}$ plane.

2. After the creep test at 850 and $900{ }^{\circ} \mathrm{C}$, a stress-induced $\gamma \rightarrow \alpha_{2}$ transformation took place. Two mechanisms can account to the process: (1) dislocations assembled at $\alpha_{2} / \gamma$ and $\gamma / \gamma$ interfaces, providing higher free energy and diffusion channels; (2) Ti preferentially enriched at interfacial dislocations and promote the thermodynamic process. In addition, $\alpha_{2}$ lamella can directly decompose into the $\omega_{\mathrm{o}}$ phase at $850{ }^{\circ} \mathrm{C}$.

3. The microstructural instability during the creep test at higher temperatures $\left(850\right.$ and $\left.900{ }^{\circ} \mathrm{C}\right)$ is more significant. The instabilities of microstructures would lead to a decrease in creep resistance.
Acknowledgements This work was financially supported by the National Natural Science Foundation of China (Nos. 51774238 and 51971176), the 2018 Joint Foundation of Ministry of Education for Equipment Pre-research (No. 6141A020332), the State Key Laboratory for Advanced Metal and Materials Foundation (No. 2014-ZD06) and the Open Project of Key Laboratory for Magnetism and Magnetic Materials of the Ministry of Education, Lanzhou University (No. LZUMMM2020008). Analytical \& Testing Center in Northwestern Polytechnic University are also acknowledged sincerely for the support.

\section{References}

[1] K. Kothari, R. Radhakrishnan, N.M. Wereley, Prog. Aerosp. Sci. $\mathbf{5 5}, 1(2012)$

[2] X. Wu, Intermetallics 14, 1114 (2006)

[3] L. Cheng, J. Li, X. Xue, B. Tang, H. Kou, E. Bouzy, Intermetallics 75, 62 (2016) 
[4] M. Schloffer, B. Rashkova, T. Schöberl, E. Schwaighofer, Z. Zhang, H. Clemens, S. Mayer, Acta Mater. 64, 241 (2014)

[5] J.G. Wang, T.G. Nieh, Intermetallics 8, 737 (2000)

[6] Z.W. Huang, Acta Mater. 56, 1689 (2008)

[7] T. Ye, L. Song, Y. Liang, M. Quan, J. He, J. Lin, Mater. Charact. 136, 41 (2018)

[8] L. Song, X. Xu, L. You, Y. Liang, Y. Wang, J. Lin, Acta Mater. 91, $330(2015)$

[9] Z.W. Huang, Intermetallics 37, 11 (2013)

[10] Z.W. Huang, W.E. Voice, P. Bowen, Mat. Sci. Eng. A 329-331, $435(2002)$

[11] Z.W. Huang, W. Voice, P. Bowen, Intermetallics 8, 417 (2000)

[12] R. Chen, Q. Wang, Y. Yang, J. Guo, Y. Su, H. Ding, H. Fu, Intermetallics 93, 47 (2018)

[13] Q. Wang, R. Chen, D. Chen, Y. Su, H. Ding, J. Guo, H. Fu, Mat. Sci. Eng. A 767, 138393 (2019)

[14] B. Cao, J. Yang, X. Wang, Y. Wu, R. Hu, J. Alloys Compd. 740, $1140(2018)$

[15] R.C. Pond, P. Shang, T.T. Cheng, M. Aindow, Acta Mater. 48, $1047(2000)$

[16] R. Darolia, J.J. Lewandowski, C.T. Liu, P.L. Martin, D.B. Miracle, M.V. Nathal eds. (TMS, Warrendale, 1993), p. 208

[17] Q. Wang, G.Q. Chen, K. Wang, X.S. Fu, W.L. Zhou, Mater. Sci. Eng., A 756, 149 (2019)

[18] T.E.J. Edwards, F. Di Gioacchino, A.J. Goodfellow, G. Mohanty, J. Wehrs, J. Michler, W.J. Clegg, Acta Mater. 163, 122 (2019)
[19] F. Appel, P.A. Beaven, R. Wagner, Acta Metall. Mater. 41, 1721 (1993)

[20] V.K. Vasudevan, M.A. Stucke, S.A. Court, H.L. Fraser, Philos. Mag. Lett. 59, 299 (1989)

[21] T.E.J. Edwards, F. Di Gioacchino, A.J. Goodfellow, G. Mohanty, J. Wehrs, J. Michler, W.J. Clegg, Acta Mater. 166, 85 (2019)

[22] F. Appel, Philos. Mag. 85, 205 (2005)

[23] Y.Q. Sun, P.M. Hazzledine, J.W. Christian, Philos. Mag. A 68, 471 (1993)

[24] F. Ernst, M.W. Finnis, D. Hofmann, T. Muschik, U. Schönberger, U. Wolf, M. Methfessel, Phys. Rev. Lett. 69, 620 (1992)

[25] E. Abe, S. Kajiwara, T. Kumagai, M. Nakamura, Philos. Mag. A 75, 975 (1997)

[26] F. Appel, J.D.H. Paul, M. Oehring (Wiley, Weinheim, 2011), p. 117

[27] X. Wang, J. Yang, L. Song, H. Kou, J. Li, H. Fu, Intermetallics 82, $32(2017)$

[28] Z.C. Luo, H.P. Wang, J. Mater. Sci. Technol. 40, 47 (2020)

[29] H. Zhang, H. Kou, J. Yang, J. Wang, J. Li, X. Xue, Intermetallics 60, 13 (2015)

[30] G.K. Dey, R. Tewari, S. Banerjee, G. Jyoti, S.C. Gupta, K.D. Joshi, S.K. Sikka, Acta Mater. 52, 5243 (2004)

[31] L. Song, J. Lin, J. Li, Mater. Des. 113, 47 (2017) 